\title{
OCUPAÇÕES URBANAS EM FORTALEZA: POPULAÇÃO NÔMADE, DIREITOS E MORADIA
}

\author{
URBAN OCCUPATIONS IN FORTALEZA: NOMAD POPULATION, RIGHTS AND \\ HOUSING
}

\author{
${ }^{1}$ Lara Capelo Cavalcante
}

\section{RESUMO}

Os interesses e forças que regem os processos de ocupações urbanas das cidades contemporâneas são muito complexos e diversificados. Nesse variado campo de possibilidades (VELHO, 2008b), o presente trabalho tem por objetivo ampliar o conhecimento que dispomos sobre o processo de ocupação da terra urbana em Fortaleza, realizado por uma parcela da população a qual eu denominei de nômades urbanos. São pessoas que residem em lugares classificados como favelas, assentamentos irregulares, áreas de risco e conjuntos habitacionais e encontram-se, geralmente, envolvidas em constantes movimentos de territorialização e desterritorialização (DELEUZE e GUATTARI, 1997) dos seus espaços de moradia. As ocupações urbanas realizadas pela população nômade são ações coletivas (BECKER, 1977), formadas por uma rede complexa e diversificada de atores e poderes sociais, que se apropriam de discursos originários de múltiplos domínios (jurídicos, religiosos, provenientes de associações de moradores), tecendo um jogo cotidiano na defesa de seus interesses. Nesse sentido, este trabalho tem por objetivo fazer um estudo sobre as regras jurídicas que disciplinam a questão fundiária urbana, não se limitando a analisá-las do ponto de vista do direito positivo, mas procurando fazer uma investigação etnográfica sobre como os agentes envolvidos nesse processo se apropriam dessas regras jurídicas e negociam o significado de suas ações (GEERTZ, 2008) ao estabelecerem hierarquias de credibilidade (BECKER, 1977) e categorias de classificação (DURKHEIM e MAUSS, 1969) que fazem parte de universos de discursos múltiplos, mais ou menos discrepantes, revelando mundos diferentes, parciais e simultâneos, nos quais se movimentam. Com isso, quero dizer que a cultura jurídica, referente à realidade na qual está inserida a população nômade, não surge de uma única fonte e não é monolítica, ao contrário está expressa no multiculturalismo das sociedades complexas (BARTH, 2000). Através do estudo de diferentes territórios da cidade de Fortaleza e de sua Região Metropolitana, procurei fazer uma espécie de mapeamento simbólico do movimento da vida dos nômades urbanos, refletindo sobre a complexidade sociológica das estruturas espaço-temporais sob as quais se assentam os fenômenos da alteridade e da experiência humana no mundo contemporâneo (ROCHA e ECKERT, 2005).

Palavras-chave: Palavras-chave: cidade, Nômades, Direitos, Moradia, Ocupações urbanas

\footnotetext{
${ }^{1}$ Doutora em Sociologia pela Universidade Federal do Ceará, UFC - Ceará (Brasil). Professora de Direito pela Universidade Federal do Ceará, UFC - Ceará (Brasil). E-mail: laracapelo@ hotmail.com
} 


\begin{abstract}
The motivations and forces that control the processes of occupation of urban areas of contemporary cities are rather complex and diverse. On this large field of possibilities (VELHO, 2008b) this paper aims at expanding the knowledge we have about the urban territory occupation process in Fortaleza, carried by a part of the population that I named urban nomads. These are people who live in places called favelas, irregular settlements, risk areas and housing estates, and that are, regularly, involved in territorialisation and deterritorialisation (DELEUZE e GUATTARI, 1997) of their home places. The urban occupation by the nomad population is a collective action (BECKER, 1997), formed by a complex and diversified net of actors and social powers, that take their discourses from different areas (juridical, religious, originated from community assemblies) making their way protecting their priorities on a daily basis. Having that in mind, this paper aims at investigating juridical laws that regulate the urban land titling issue. We not only analyse them from the positive laws point of view; we try to do an ethnographic research on how the agents involved in that process use these juridical laws negotiating the meaning of their actions (GEERTZ, 2008), and creating hierarchies of credibility (BECKER, 1977) and categories of classification (DURKHEIM and MAUSS, 1969). These are part of a universe of multiple discourses that can have sometimes discrepancies, revealing different, partial and simultaneous worlds in movement. That means that the juridical culture referred to the nomad population does not come from a single font and is not monolithic, inflexible, but is expressed in the multiculturalism of complex societies (BARTH, 2000). Through studies of different territories of the city of Fortaleza and its metropolitan area, I tried to somehow build a symbolic mapping of the movement of urban nomads, reflecting upon the sociological complexity of space-time structures on which events of the human alterity and experience are established on the contemporary world (ROCHA and ECKERT, 2005).
\end{abstract}

Keywords: Key words: city, Nomads, Rights, Housing, Urban occupations 


\section{1- Introdução}

Os interesses e forças que regem os processos de ocupações urbanas das cidades contemporâneas são muito complexos e diversificados. Nesse variado campo de possibilidades (VELHO, 2008b), o presente trabalho tem por objetivo ampliar o conhecimento que dispomos sobre o processo de ocupação da terra urbana em Fortaleza, realizado por uma parcela da população a qual eu denominei de nômades urbanos. São pessoas que residem em lugares classificados como favelas, assentamentos irregulares, áreas de risco e conjuntos habitacionais e encontram-se, geralmente, envolvidas em constantes movimentos de territorialização e desterritorialização (DELEUZE e GUATTARI, 1997) dos seus espaços de moradia. As ocupações urbanas realizadas pela população nômade são ações coletivas (BECKER, 1977), formadas por uma rede complexa e diversificada de atores e poderes sociais, que se apropriam de discursos originários de múltiplos domínios (jurídicos, religiosos, provenientes de associações de moradores), tecendo um jogo cotidiano na defesa de seus interesses. Nesse sentido, este trabalho tem por objetivo fazer um estudo sobre as regras jurídicas que disciplinam a questão fundiária urbana, não se limitando a analisá-las do ponto de vista do direito positivo, mas procurando fazer uma investigação etnográfica sobre como os agentes envolvidos nesse processo se apropriam dessas regras jurídicas e negociam o significado de suas ações (GEERTZ, 2008) ao estabelecerem hierarquias de credibilidade (BECKER, 1977) e categorias de classificação (DURKHEIM e MAUSS, 1969) que fazem parte de universos de discursos múltiplos, mais ou menos discrepantes, revelando mundos diferentes, parciais e simultâneos, nos quais se movimentam. Com isso, quero dizer que a "cultura jurídica", referente à realidade na qual está inserida a população nômade, não surge de uma única fonte e não é monolítica, ao contrário está expressa no multiculturalismo das sociedades complexas (BARTH, 2000).

A explosão demográfica nas cidades, a desigualdade social e econômica, a falta de desenvolvimento de políticas públicas adequadas para solucionar o problema do déficit habitacional são fatores que influenciam a população segregada - habitante de favelas, áreas de risco, assentamentos irregulares e conjuntos habitacionais - a tornar-se nômade dentro do espaço urbano, sofrendo um contínuo rompimento de suas condições de moradia, trabalho, vizinhança e laços de sociabilidade. Além disso, os barracos ou casas "ilegais", assim como, os apartamentos localizados em conjunto habitacionais tornam-se, muitas vezes, bens de valor e demanda certa no mercado imobiliário 
clandestino, possibilitando potencias permutas e negociações que também estimulam as travessias dos nômades urbanos.

Park, ao expor a necessidade de definir um ponto de vista e indicar um programa para o estudo da vida urbana, chama a atenção para a importância de se questionar sobre as forças e tensões que tendem a deixar a população urbana instável. Nesse sentido, o autor aponta as seguintes perguntas como importantes questões epistemológicas: "Que parte da população é flutuante? De que elementos, isto é, raças, classes etc. se compõe essa população? [...] Que proporção da população é constituída por nômades, biscateiros e ciganos?”. (1967, p.36, grifo meu)

O movimento de desterritorialização da população nômade não se resume às ocupações e deslocamentos geográficos, onde territórios correspondem comumente a um lugar fixo. Aqui o ato de desterritorializar-se e reterritorializar-se adquire também outra significação, qual seja, um sentido subjetivo do território como espaço vivido, como representante de toda uma série de comportamentos nos tempos e espaços sociais, culturais, estéticos e cognitivos (GUATTARI e ROLNIK, 1986). É nesse sentido que reputo importante o conhecimento da experiências de vida de alguns informantes que encontrei em campo, no sentido de expor processos de desterritorialização não só geográficos, mas também afetivos, cognitivos e existências, tentando responder às seguintes perguntas:

Que espaço social está destinado à população que é excluída do mundo da legalidade? Onde habita a população clandestina, que vive de uma economia informal? Como os nômades se apropriam das normas que regem a questão fundiária urbana, relacionadas ao direito individual à propriedade privada (caput e inciso XXII do art. $5^{\circ}$; inciso II do art. 170 da Constituição Federal de 1988) e ao direito social à moradia (artigo $6^{\circ}$, caput, da Constituição Federal de 1988) e criam seus próprios conceitos de conduta legítima?

Dentro do diversificado universo de ações envolvidas nos processos de ocupação da terra urbana em Fortaleza, a presente pesquisa privilegia a análise do discurso jurídico, como um sistema simbólico que não se restringe a uma estrutura monolítica de poder, mas que é constituída por redes de poderes e significados móveis. A análise, portanto, não está enfocada no estudo técnico das normas jurídicas que se referem à questão fundiária urbana, mas concentra-se, principalmente, na maneira como 
a população nômade e outros atores que estão envolvidos nesse contexto se apropriam dessas normas para negociarem suas ações. Nesse sentido, esta pesquisa pretende responder a questões do tipo: até que ponto as normas jurídicas produzidas pelo Estado sobre à questão fundiária urbana produzem significados compartilhados pelos agentes que estão envolvidos nesse drama social? Como os interesses são negociados? Que marca o direito à propriedade e à moradia deixa no produto cultural quando este é criado e exercido pela população nômade? Quais são os universos jurídicos fundiários criados por essa população?

Acredito que esses questionamentos, se aplicados de modo sistemático, oferecem meios para descobrir e mapear as formas significativas de coerência na cultura, não em busca de estruturas acabadas, mas a procura da identificação de processos sociais.

Nesse sentido, a etnografia que proponho realizar é ela mesma nômade, não diz respeito somente a um determinado bairro da cidade, mas a lugares que, dentre outros, constituem expressão emblemática do modo de vida dessa população. Mas, como não é possível fazer uma etnografia de todos os percursos dos nômades urbanos, resolvi estudar as suas travessias de uma forma mais intensa a partir da história de vida de alguns informantes ou do estudo de determinadas situações e lugares. A escolha do campo empírico se deu pelo desenvolvimento de um olhar cotidiano sobre processos de remoção de favelas e de tentativas de ocupação de terra na cidade de Fortaleza.

Desenvolvi, desse modo, uma observação flutuante na cidade de Fortaleza, nos termos de Marcio Goldman (1995) ao falar dos novos métodos de pesquisa realizados nas sociedades complexas. Trata-se, na realidade, de continuar a fazer o que sempre costumamos a fazer quando investigamos nossa própria sociedade, desenvolvendo uma observação intensiva e prolongada feita a partir do interior de suas atividades. Tendo, no entanto, o cuidado de buscar sempre certo afastamento, uma tomada de distância.

Desse modo, desenvolvi uma observação não só participante, mas também, flutuante na cidade de Fortaleza, exercida em bairros diversos, sobre as diferentes formas de expressão do nomadismo urbano. A complexidade da minha pesquisa de campo, no entanto, não faz da mesma uma variedade superficial de observações empíricas. Ao contrário, as histórias, episódios e lugares pesquisados fazem parte de um mesmo ethos, no que diz respeito às diversas formas e expressões do nomadismo 
urbano. O fato de a pesquisa versar sobre territórios diferentes da cidade não impediu que eu pudesse adentrar na realidade cotidiana dos locais pesquisados e da vida dos informantes, percebendo que estas são bem mais complexas do que a leitura feita pelo senso comum.

É nesse sentido que quero chamar a atenção para a importância do desenvolvimento de um olhar antropológico sobre a questão fundiária urbana na qual está envolvida a população nômade. Com isso, não pretendo refutar as pesquisas dos urbanistas, arquitetos e juristas do meio ambiente urbano sobre às más condições de vida nas favelas ou áreas de risco. Quero, no entanto, procurar entender como a questão do direito à moradia e do direito à propriedade privada se dá a partir do ponto de vista dos moradores da favela, da área de risco e do conjunto habitacional para poder situar o problema ao nível dos acontecimentos e experiências reais desse universo e não de acordo com opiniões do senso comum, ou de outros extratos sociais alheios a essa realidade. De acordo com Gilberto Velho:

A lição da Antropologia é que o primeiro passo, o mais fundamental é procurar ouvir e entender a visão de mundo dos grupos sociais que vivem diretamente essas situações e procurar perceber seus pontos de vista, com o mínimo de preconceitos e sem paternalismos. $(1989$, p.10)

Desse modo, os diferentes bairros que pesquisei na cidade de Fortaleza constituem expressão emblemática, cada qual ao seu modo, das diversas formas de nomadismo urbano. Os diferentes campos escolhidos refletem realidades múltiplas, compreendendo desde aqueles que empreendem uma forte resistência à remoção, passando pelos que estão sempre mais vulneráveis a permanecer num estado de nomadismo, até os que fazem das ocupações urbanas um meio de vida, um trabalho, uma forma de ganhar dinheiro através da comercialização de lotes de terras.

Nesse sentido, este trabalho procura fazer uma descrição densa dos seguintes lugares pesquisados, entre os anos de 2007 a 2011 na cidade de Fortaleza: a) Praia das Goiabeiras, localizada na Barra do Ceará, dando enfoque a trajetória de resistência de uma moradora, chamada Dona Íris, contra o processo de remoção de milhares de famílias para implantação de um projeto de intervenção urbana, chamado Costa-Oeste, desenvolvido pelo Governo do Estado do Ceará; b) Cristo Redentor, localizando também no Grande Pirambu, descrevendo a trajetória de vida de uma típica nômade 
urbana, nas suas travessias em diferentes moradias na cidade e o processo de resistência do grupo folclórico representado pelo Boi Juventude contra a remoção da sede do mesmo para a construção de uma avenida na orla; c) Praia do Futuro, localizada no litoral leste da cidade, próxima a Barra do Rio Cocó, analisando a tentativa de ocupação a vários terrenos do bairro; d) Favela da Maravilha, localizada ao lado da Avenida Agunambi, no Bairro de Fátima, analisando o processo de remoção de mais de duzentas famílias que residiam na favela para um conjunto habitacional construído do outro lado da avenida.

É importante esclarecer que, no desenvolvimento deste trabalho, não me preocupei com uma homogeneidade teórica. Mas, trabalhei com várias categorias de pensamento, emanadas de autores diversos que foram surgindo a partir de necessidades teóricas relacionadas à complexa realidade empírica que encontrei em campo.

Dada a complexidade do campo empírico e a grande quantidade de material coletado a partir de entrevistas, fotografias, filmagens e observação participante, o presente artigo procura expor os traços comuns que foram encontrados no desenvolvimento da pesquisa em Fortaleza, com o objetivo de refletir sobre as questões acima expostas.

\section{2 - Nômades urbanos em Fortaleza}

No desenvolvimento da minha pesquisa, pude constatar a existência de pelo menos duas categorias de nômades urbanos, ou seja, de pessoas que estão sempre sujeitas, de modo temporário ou permanente, a vivenciar processos de territorialização e desterritorialização de seu local de moradia.

Em primeiro lugar, está aquela parcela da população urbana que, por não ter condições materiais de adquirir ou alugar uma moradia dentro das exigências legais, permanece num estado de nomadismo por conta de alguns fatores, que vão desde questões existenciais, de condição de vida, a problemas relacionados à ação da natureza, à intervenção do Poder Público ou do proprietário do imóvel. Para ilustrar essa situação, lembrei-me de uma entrevista que fiz com uma moradora do Bairro Cristo Redentor, no Pirambu. Nesse momento, escreverei sobre alguns percursos traçados pela moradora, referentes às diversas habitações que a mesma ocupou em Fortaleza, como forma de exemplificar a primeira categoria de nômade. 
Trata-se de uma senhora de 73 anos de idade que veio da cidade de Itapajé, interior do Estado do Ceará, com quatorze anos de idade. A moradora era órfã de pai e mãe e residia em Itapajé com seus avós. Segundo me informou, ela era muito maltratada pelos mesmos. Por isso, resolveu fugir para Capital. Quando chegou a Fortaleza, foi morar na casa de uma tia, mas teve problemas de relações familiares e fugiu novamente. Como ela era muito jovem e não teve mais apoio dos parentes, passou alguns anos trabalhando e morando em casa de famílias como empregada doméstica. Quando ela completou vinte anos, o Padre Hélio, que ajudava a população carente habitante da região do Grande Pirambu em Fortaleza, the deu uns pedaços de madeira. Com o material, ela construiu um quarto na beira da Lagoa do Mel. Nesse período, a moradora ganhava a vida lavando roupa e morava sozinha com uma filha. Mas, logo teve que sair do quartinho construído na beira da lagoa porque a água derrubou tudo. Então, a moradora mudou-se para uma casa construída na beira de outra lagoa, na Castanhola, que também sofria os mesmos problemas de alagamento. Por isso, a informante teve que se mudar novamente. Ela casou com um pescador e foi morar com o mesmo na casa da sogra. Depois, o casal comprou um quartinho. Na época do Governo do Tasso, a

moradora foi até o Cambeba $^{1}$ e ganhou um material de construção. Então, ela e o marido construíram uma casa na beira da praia. Ela disse que a casa era boa e grande. Mas, a maré todo dia levava um pedacinho da sua casa.

O relato sobre o nomadismo da moradora retrata a realidade de muitos brasileiros que migram do interior para a capital em busca de melhores condições de vida. Mas, quando chegam à cidade não encontram emprego que lhes garantam a possibilidade de adquirir uma moradia digna. Os nômades, desse modo, têm que improvisar habitações construídas em áreas sem infra-estrutura, sujeitas à ação da natureza, com deslizamentos e alagamentos. Além disso, os locais onde constroem suas moradias são, geralmente, classificados como foco de doenças e marginalidade. A fala da moradora constitui, assim, a imagem dos migrantes cearenses que ao chegarem a Fortaleza, encontraram um território de desigualdade social que impulsiona essa população a uma reinvenção constante da vida, construindo moradias "ilegais", "irregulares" e "clandestinas". O depoimento revela, ainda, o drama individual dessa migrante do sertão que no diversificado campo de possibilidades (VELHO, 2008 b),

típico das sociedades complexas contemporâneas, trilhou seu mapa físico e subjetivo na

\footnotetext{
${ }^{1}$ Local onde se localiza o centro administrativo do Governo do Estado.
} 
cidade de Fortaleza. É nessa diversificada dimensão sociocultural que os indivíduos se fazem, são constituídos, feitos e refeitos, construindo suas próprias trajetórias existenciais.

O segundo tipo de nômade que encontrei em campo é aquele que, de um modo geral, ocupa terrenos urbanos não para solucionar uma questão referente à falta de moradia, mas para vender para aqueles interessados em adquirir uma casa, praticando uma espécie de "especulação imobiliária clandestina". Esse segundo tipo de nômade não se confunde com a situação de famílias que são removidas para conjuntos habitacionais e, por não conseguirem se adaptar, vendem o imóvel e voltam para a favela ou outros lugares considerados áreas de risco. Estou falando de pessoas que têm como um das suas formas de sobrevivência a prática de ocupar imóveis, sejam lotes vazios ou unidades em conjuntos, para comercializar e ganhar dinheiro com isso.

Em pesquisa realizada no bairro das Goiabeiras, através do depoimento de vários moradores, coletei dados importantes sobre os movimentos da população na busca por moradia. Assim, pude constatar que o processo de ocupação de terrenos urbanos realizado pelos nômades é muito mais complexo e diversificado do que eu imaginava, uma vez que não é feito somente por aqueles desprovidos de moradia Os ocupantes, ao conquistarem a posse de um lote em um assentamento irregular ou quando são "beneficiados" com o direito de morar em uma unidade habitacional oferecida pelo Poder Público, nem sempre desejam consumir o imóvel somente como o objetivo de utilizá-lo para fins de moradia ou de trabalho, interessa-lhes, também, dispor do bem como um meio de troca, fazendo do mesmo um objeto de negócio, de venda. De acordo com Souza:

O poder público ao enfatizar a habitação como um direito, passa a negar a sua condição de bem de mercado e tenta impor o direito concedido. Por sua vez, a população, na sua luta pelo direito à habitação, parece pretender o direito de acesso ao bem de mercado. (1993, p. 229, grifo meu)

Parece-me, assim, que o significado que os nômades imprimem ao processo de luta pela terra urbana, não se limita apenas a reivindicar o direito à moradia, caracterizado como um direito social, previsto e garantido constitucionalmente. Mas, revela também a necessidade de conquistar o direito de propriedade de um bem imóvel, caracterizado como um direito individual, também previsto e garantido 
constitucionalmente, seja para consumi-lo como local de moradia e trabalho, seja para poder dispor do mesmo como um bem de mercado, negociando o imóvel e lucrando com a operação. É nesse contexto, que encontrei o segundo tipo de nômade, ou seja, pessoas que fazem do processo de ocupação um meio de vida, uma forma de ganhar dinheiro. Transcrevo um trecho do depoimento de uma moradora do bairro das Goiabeiras:

Há minha filha, quem invade não é quem precisa de moradia, pois quem não tem onde morar se sente tão humilhado e não tem coragem para fazer isso. Geralmente, quem invade são grupos organizados, que ocupam o terreno para depois construir e vender a casa. Além disso, muitas pessoas que vão morar em conjuntos habitacionais, construídos pelo Estado, depois vendem suas casas e vão ocupar beiras de mangues, rios ou lagoas.

Posteriormente, no desenvolvimento da pesquisa de campo, me deparei com diversas situações que confirmaram essa situação. Na observação do movimento de ocupação de terrenos urbanos no bairro da Praia do Futuro, pude constatar que grande parte das pessoas que participou do evento já possuía casa e estavam ali para conseguir mais um pedaço de terra para negociar ou para construir casas para alugar ou vender. Além disso, colhi vários depoimentos de pessoas que ao saberem que iria ocorrer uma intervenção urbana em uma determinada área da cidade, por parte do poder público, tratavam logo de construir uma casa no local ou, até mesmo um negócio, com padaria ou bar, com o intuito de receber indenização pela benfeitoria.

Parece-me, assim, que o movimento de disputa pela terra urbana é envolvido não só pela questão da falta de habitação, mas também por uma questão de trabalho, do desenvolvimento de uma economia informal, ou seja, de pessoas que realizam ocupações urbanas com o intuito de empreender uma comercialização imobiliária paralela às comercializações legalizadas de imóveis.

Os órgãos de comunicação de massa, as declarações de entidades oficiais e do senso comum, de um modo geral, marcam intensamente e de forma diferenciada, os nômades urbanos no que diz respeito ao seu modo de habitar na cidade, denominando os mesmos de "invasores", "aproveitadores", "safados", pois muitas ocupações são feitas no intuito de vender os lotes. Os nômades também são taxados como "pessoas que não querem melhorar de vida", que preferem continuar "favelados", pelo fato de que 
muitos, aos serem removidos da favela para conjuntos habitacionais, negociam essas moradias e voltam a ocupar novas "áreas de risco". O senso comum afirma que essas pessoas não conseguem se adaptar a moradias dignas e limpas que preferem continuar na miséria.

No entanto, durante o desenvolvimento da minha pesquisa, percebi que nesse processo existem visíveis fronteiras de valores diferentes e conflitantes que separam os agentes envolvidos. Se, por um lado, o senso comum tem uma visão generalista e superficial a respeito da ação dos nômades urbanos. Por outro, essa população é capaz de construir seus próprios critérios de classificação, que também variam e nem sempre são homogêneos, podendo até ser discrepantes, pois são formados a partir da posição que cada um ocupa no sistema (se é líder comunitário, se está vinculado a algum órgão público, ser recebe apoio da Igreja, de advogados ou vereadores) e dos interesses que estão envolvidos na ação (de ocupar para consumir o bem como moradia ou para negociá-lo no mercado).

Um exemplo de que os nômades urbanos criam seus próprios critérios de classificação, é a fala expressa no depoimento citado, afirmando que no processo de luta pela terra estão envolvidos tanto aqueles que "precisam de moradia" quanto os que "não precisam", mas participam da ação de ocupação com o intuito de negociar ou vender para quem "realmente precisa de moradia".

A partir dessa realidade, percebi que, no processo de ocupação dos espaços da cidade pelos nômades, não há um discurso puro sobre o significado da ação dessas pessoas, mas uma multiplicidade de discursos compostos por um emaranhado de linhas provenientes de agentes e interesses diversos que se entrecruzam a todo instante.

Diante dessa complexa realidade na qual estão inseridos os nômades urbanos, pude observar que os processos de ocupação dos espaços da cidade tecidos por essa população podem variar de acordo com o sentido que a mesma imprime ao direito à moradia, podendo concebê-lo como um "direito natural" de morar - que se consolida em face da disponibilidade dos vazios urbanos - ou como um direito social à moradia garantido constitucionalmente, assumindo um teor de luta institucionalizada. No entanto, independente da concepção jurídica que os nômades urbanos imprimam ao movimento de ocupação de terra, a ação dessa população tem em comum as seguintes características: a) é realizada por uma parcela da população que, de um modo geral, não 
tem recurso financeiro para adquirir uma moradia dentro das condições de legalidade, exigidas pelo direito de propriedade, e, por conta disso, habitam de maneira informal e clandestina; b) é tecida por uma rede de interesses, poderes e agentes, que não se restringe a atuação dos nômades urbanos, envolvendo: políticos, vereadores, deputados, membros do Poder Executivo, secretarias e órgãos do Poder Público, advogados, organizações não governamentais em prol do direito à moradia, policiais, seguranças particulares dentre outros, conforme será demonstrado ao longo desse trabalho; c) é motivada pela tentativa de acesso a um bem imóvel não somente com a finalidade de consumi-lo como local de moradia ou trabalho, mas também como o objetivo de dispor do mesmo como um bem de mercado, para negociá-lo ou vendê-lo.

Essas características põem em questão fronteiras que separam as noções de legalidade e ilegalidade, de normalidade e anormalidade, entre os diferentes mundos que estão envolvidos no processo de disputa pela terra urbana. De acordo com Souza:

A negação do valor da terra, veiculada pela população politicamente organizada que reivindica o direito de ocupá-la para consumo, encontra-se na base do discurso do direito à moradia, enquanto direito natural daquele que ocupa a terra. Levada aos Movimentos Sociais Urbanos como projeto político- ideológico pelos assessores, tal negação não é incorporada pela população. No momento em que esta consolida o direito ao bem, considera-o um bem de mercado e afirma nele os valores da propriedade. (1993, p.231)

Assim, a ação dos nômades urbanos transcende a busca por uma habitação, muito embora seja na bandeira do direito à moradia que essa população encontra legitimidade para a sua ação. Ao concretizarem uma ocupação urbana, seja pela conquista ilegal da posse de lotes vazios ou por algum processo de regularização fundiária previsto em lei, os nômades urbanos entendem estar realizando não só um direito relacionado à moradia, mas também à propriedade do bem, passando a exercer na prática todos os poderes inerentes ao direito de propriedade, inclusive o de dispor do bem, utilizando-o como um objeto que pode ser negociado em um mercado.

Nessa complexa realidade, resolvi classificar como tipos ideais, no sentido metodológico utilizado por Weber (1994), dois tipos de nômades. A classificação que exporei a seguir tem por objetivo, desse modo, funcionar como um instrumento de interpretação e investigação da infinitude do real. Na diversificada realidade do 
nomadismo urbano que encontrei em minha pesquisa, escolhi alguns elementos do comportamento das pessoas investigadas que considero mais relevante para a explicação desse drama social. A classificação que desenvolvi corre o risco de acentuar certos traços da ação dos nômades urbanos em detrimento de outros, o que pode conferir certa unilateralidade ao modelo puro. De acordo com o pensamento de Weber, os tipos ideais são utópicos, funcionam como um facilitador metodológico para investigação da complexidade do real. Os conceitos de nômades que elaborei foram construídos, assim, a partir de traços considerados essenciais e segundo critérios que pretendem explicar o fenômeno investigado:

a) Nômades moradores: são os que, ao realizarem ocupações urbanas, em um primeiro momento, desejam consumir o imóvel como bem de uso, para fins de moradia ou trabalho. Neste caso, a pessoa ou família que realizou a ocupação pode nunca se interessar em se desfazer do bem. No entanto, posteriormente à concretização da ocupação, por motivos diversos - que variam desde questões pessoais e existências, tais como separação, divórcios, mudança de local de trabalho, até questões econômicas, impulsionadas pela valorização do imóvel adquirido -, os nômades urbanos podem vender o bem para outras pessoas e tornar a ocupar novos territórios na cidade. É possível, ainda, que esse segundo tipo de nômade abandone o local ocupado, sem vendê-lo ou negociá-lo. Tal fato pode acontecer por diferentes motivos, com: ação da natureza, no caso de enchente ou deslizamento de terra, por exemplo, que destrói ou ameaça a moradia do ocupante; exercício do direito de propriedade, quando o legítimo proprietário do imóvel reivindica o bem, expulsando os ocupantes; atuação do poder público, com a remoção de uma favela.

b) Nômades negociantes: são os que, ao realizarem ocupações urbanas, praticam a ação não com o intuito de adquirir um lote de terra para fazer dele a sua moradia, mas para vendê-lo para outras pessoas. Neste caso, a ocupação urbana assume o sentido de um negócio. O imóvel é consumido pelos nômades como um bem de mercado, adquirindo essa ação a característica de um meio de vida, de um trabalho exercido dentro de um mercado informal de negociação de terra urbana.

É importante esclarecer, no entanto, que mesmo na primeira situação, os nômades urbanos não concebem o bem ocupado somente como um direito à moradia (bem de uso para fins de moradia ou trabalho), mas também, como um direito à 
propriedade privada (bem de mercado, negociável). Embora essa última característica pareça ser mais acentuada no segundo tipo de nômade, ela perpassa ambas as categorias. Assim, uma família pode, por exemplo, ocupar um terreno de forma clandestina e, após efetivada a ocupação, construir sua casa e ali residir por certo período de tempo. Posteriormente, a família pode sair do local, não por conta de uma ação da natureza (alagamento ou deslizamento, por exemplo), nem por conta da reivindicação do legítimo proprietário do terreno ou pelo desenvolvimento de uma política de intervenção urbana. Mas, porque apareceu outra família interessada em comprar a casa, oferecendo uma quantia em dinheiro. Neste caso, os moradores originários vendem a posse do imóvel, lucram com a operação e depois vão ocupar outras áreas da cidade.

A classificação que expus acima foi realizada com o intuito de facilitar a compreensão da ação dos nômades urbanos nos seus movimentos de territorialização e desterritorialização em relação às ocupações urbanas e aos seus locais de moradia. No entanto, neste trabalho, dada a complexidade da realidade investigada, optei por me referir, na maioria das vezes, a categoria nômade urbano indistintamente, sem especificar o tipo ideal envolvido na situação. Assim, somente em algumas passagens desse texto, quando reputo necessário ao esclarecimento da situação estudada, é que me refiro às classificações acima expostas.

De acordo com Gilberto Velho (2003a), nas sociedades complexas modernocontemporâneas, há uma tendência de constituição de identidades a partir de um jogo intenso e dinâmico de papeis sociais, que se associam a múltiplas experiências e níveis de realidades, muitas vezes, conflituosos e contraditórios. As sociedades complexas apresentam uma inarredável dimensão sociocultural, constitutiva de modelos, paradigmas e mapas. É nesse vasto campo de possibilidades que os indivíduos se fazem, são constituídos, feitos e refeitos, através de suas trajetórias existenciais, num jogo constante de permanência e mudança.

Em minha pesquisa, desejo mostrar o caráter tênue e fluido das fronteiras entre o mundo oficial (do direito à moradia e à propriedade privada, do desenvolvimento de projetos de ordenação do espaço urbano, tais como os de remoção de favelas e de construção de conjuntos habitacionais) e um mundo, relativamente, subterrâneo, consistente nas apropriações diversas que os nômades urbanos fazem das normas 
jurídicas que regulamentam a questão fundiária nas cidades e dos projetos de intervenção urbana desenvolvidos pelo Estado.

Nesse sentido, esta pesquisa tem duas dimensões: a primeira diz respeito às múltiplas apropriações dos discursos jurídicos que giram em torno da questão fundiária urbana relacionada ao direito à moradia e à propriedade privada; a segunda se refere a ação dos nômades urbanos atuando com uma linha de fuga (DELEUZE E PARNET, 1998) na constante reinvenção dos espaços de moradia na cidade. Essas dimensões serão fundidas no mapeamento das redes de relações (ZALUAR, 2006) e de significados (GEERTZ, 2008), que se formam na disputa pela terra urbana em Fortaleza e que são tecidas pela atuação de diversos micropoderes (FOUCAULT, 2008), como estratégia metodológica de suma importância.

Segundo Geertz (2008), a pesquisa antropológica deve buscar a expansão do universo do discurso humano. Esse é um objetivo que se encaixa muito bem ao conceito de cultura semiótico. A cultura é um sistema entrelaçado de signos interpretáveis, um contexto no qual os fenômenos sociais devem ser descritos com densidade.

Em se tratando do tema sob pesquisa, isso significa que as descrições, de como os nômades urbanos traduzem o saber jurídico sobre as leis que versam a respeito da questão fundiária urbana, devem ser realizadas em termos das construções que a população faz das normas e de si mesma. Esta pesquisa, portanto, procura fazer uma descrição densa da forma como a população nômade concebe a ideia de direitos sociais à moradia e à propriedade privada e de como a mesma se apropria das normas jurídicas, criando sues próprios conceitos de conduta legítima. É importante lembrar, entretanto, que os textos antropológicos são eles mesmos interpretações e, na verdade, de segunda e terceira mão, pois somente um "nativo" faz a interpretação em primeira mão da sua cultura (GEERTZ, 2008).

Nesse sentido, este trabalho faz uma investigação a respeito de como as travessias dos nômades urbanos moldam os espaços da cidade, no exercício de suas práticas cotidianas de apropriação e reinvenção do modo de viver e habitar. E qual o significado que essa população atribui a sua intermitente trajetória urbana, fazendo uso de discursos jurídicos que ora afirmam, ora negam, ora transcendem o direito estabelecido pelo Estado. Assim, um dos capítulos da presente tese destina-se a descrever com densidade as diferentes formas de nomadismo urbano e suas implicações jurídicas. 
Para refletir sobre essas questões é interessante pensar com Geertz (2008). Segundo o autor a pesquisa etnográfica tem por objeto uma hierarquia estratificada de estruturas significantes. Ao fazer uma descrição densa, o etnógrafo deve estar atento à multiplicidade de estruturas conceituais complexas, que muitas vezes estão sobrepostas ou entrelaçada umas às outras de maneira irregular e aparentemente imperceptível. A tarefa do etnógrafo consiste, portanto, em desvendar as teias de significados às quais estão emaranhadas as ações coletivas, determinando a sua base social e a sua importância.

Desse modo, procurei escutar os nômades urbanos no que diz respeito a vários aspectos relacionados da realidade na qual estão inseridos, tais como: resistências contra remoções ou adesão às mesmas; estratégias e tentativas de ocupações de lotes urbanos; como se associam em grupos; quais são os mecanismos de defesa; como o exercício de poderes é negociado entre o grupo; em que medida participam do mesmo código de conduta e quais são as divergências; como se organizam em redes de poder e solidariedade social; como se apropriam das regras jurídicas para defenderem seus interesses; quais as principais causas que estimulam o nomadismo na cidade, dentre outras questões.

Este trabalho não tem por objetivo estudar o processo de disputa pela terra urbana em Fortaleza a partir da ação de movimentos sociais institucionalizados, realizados, por exemplo, por organizações não governamentais que lutam pela efetivação do direito à moradia. Isso não significa que esses movimentos não sejam importantes para a efetivação desse direito. Ao contrário, reconheço a importância fundamental dos mesmos na história da luta por acesso à habitação. No entanto, decidi lançar um olhar diferente sobre esse processo, que mostra um aspecto inusitado desse fenômeno, não tão visível quanto os movimentos sociais institucionalizados, mas que faz parte de uma luta cotidiana, de um nível capilar e minúsculo, tecida por uma parcela da população que, por diversos motivos, vive em estado de nomadismo na cidade. A tese que desenvolvi pretende, portanto, desvendar, a um nível molecular, as redes de poder, interesses $e$ significados que interagem no fenômeno de disputa pela terra urbana. É a partir desse sentido que pretendo refletir sobre as condições sociais de possibilidade do nascimento de novos direitos relacionados à questão fundiária urbana.

Os processos de ocupação da terra urbana em Fortaleza são formados por um complexo emaranhado de linhas e envolvidos por poderes e agentes diversos, tais 
como: grandes construtoras que representam o capital imobiliário e turístico em expansão; políticas públicas de ordenamento do espaço urbano empreendidas pelas diversas unidades da Federação Brasileira (União, Estado, Municípios), através de seus órgãos e secretarias; policiais; proprietários de terra e seus seguranças particulares; deputados estaduais e vereadores; advogados; associações institucionalizadas de movimentos sociais de luta por moradia; Igreja; líderes comunitários; líderes de processos de ocupação e de especulação imobiliária; nômades urbanos.

Nesse sentido, o processo de disputa pela terra urbana não tem uma composição binária, como se de um lado estivesse o Estado e o capital imobiliário e do outro os nômades urbanos. Mas é composto por uma rede de micropoderes (FOUCAULT, 2008). Assim, no estudo dos percursos traçados pela população nômade em sua travessia cotidiana em busca de moradia, não parti do centro para a periferia, do macro para o micro, tentei fazer o cominho inverso, mostrando, dentro de uma perspectiva foucaultiana (2008) que as redes de poder que se tecem nas sociedades contemporâneas não são simples extensões dos efeitos do Estado, um simples prolongamento ou uma simples difusão de seu modo de ação. As tentativas de controle da população nômade se dão em diversas instâncias e através de múltiplos mecanismos. Desse modo, os poderes não estão localizados em nenhum ponto específico da estrutura social. Funcionam como uma rede de dispositivos ou mecanismos a que nada ou ninguém escapa, a que não existe exterior possível, limites ou fronteiras. O poder no sentido trabalhado por Foucault é algo que se exerce dentro de uma relação e não está situado em um lugar privilegiado ou exclusivo, mas se dissemina por toda a estrutura social.

A partir deste trabalho pretendo contribuir para do desenvolvimento de uma visão menos preconceituosa sobre a ação dos nômades urbanos, mostrando que o modo como essas pessoas habitam na cidade e seus constantes movimentos de territorialização e desterritorialização dos seus locais de moradia constituem, na realidade, um alto grau de desenvolvimento de preservativo da vida subjetiva frente à coação das grandes cidades (SIMMEL, 2005). 


\section{3 - Conclusão}

A partir da pesquisa que desenvolvi, pude perceber que os nômades urbanos são considerados por grande parte da sociedade como pessoas que têm comportamentos desviantes ou outsiders, nos termos de Becker (2008), no que diz respeito, principalmente, ao seu modo de habitar na cidade, por serem, de um modo geral, moradores de favelas, áreas de risco e assentamentos irregulares, habitações classificadas como "anormais", "ilegais", "sujas", “foco de bandidagem”. Além disso, os nômades urbanos também são, muitas vezes, classificados como "pessoas que não querem melhorar de vida", que "preferem continuar favelados, morando em áreas de risco". Esse julgamento superficial sobre os modos de habitar na cidade dos nômades urbanos ocorre, por exemplo, quando essa população, ao ser beneficiada com uma casa ou apartamento em um conjunto habitacional, não permanece no local, vendendo para outras famílias e retornando à favela.

No entanto, existem variações na maneira como os nômades urbanos são julgados, que dependerá, geralmente, do tipo de ação exercida pelos mesmos e de quem profere o julgamento. Se os nômades urbanos ocupam um terreno para fazer dele a sua moradia, essa ação é julgada como desviante dependendo de quem a julgue: se for o proprietário do terreno o julgador, geralmente, ele vai dizer que se trata de gente desonesta, aproveitadora, que quer tirar proveito do que é dos outros, que os direitos sociais só servem para legitimar a ação dos miseráveis que querem roubar os bens de gente honesta e trabalhadora; se for uma associação ligada aos movimentos sociais de luta por moradia a julgadora, defenderá que essa população está apenas exercendo o direito humano e social à uma moradia digna, que os vazios urbanos não devem ficar ociosos como prevê a própria Constituição Federal de 1988 e o Estatuto da Cidade, pois a propriedade privada deve cumprir sua função social; se os julgadores forem advogados e vereadores ligados a comissões de direitos humanos ou que tenham interessa político na ação, com troca de votos e favores, também, poderão emitirão a mesma opinião anterior; se o julgamento for feito por agentes do Estado, provavelmente dirão que devem garantir tanto o direito de propriedade como o direito à moradia. Desse modo, a população que ocupou o terreno poderá ser removida para um conjunto habitacional ou o Estado poderá pagar ao dono do terreno um aluguel social até que encontre uma solução habitacional para as famílias. 
Em todas essas situações descritas existe um jogo tenso e permanente de preponderância entre o direito a propriedade privada (artigo $5^{\circ}$, XXII da Constituição Federal de 1988), o direito à moradia (artigo $6^{\circ}$, caput da Constituição Federal de 1988) e o princípio da função social da propriedade (artigo $5^{\circ}$, XXIII da Constituição Federal de 1988). A partir dessas questões, o interessante não é saber quais dos direitos mencionados devem prevalecer em determinada situação, mas como os diferentes atores sociais que estão envolvidos nesse processo de luta pela terra urbana se apropriam do discurso jurídico para defenderem seus interesses e como esses negociam os significados de suas ações ao estabelecerem hierarquias de credibilidade e categorias de classificação que são próprias aos diferentes grupos envolvidos e que e acabam por prevalecer a toda e qualquer tentativa de julgamento da situação por parte do direito estatal.

Percebi que os nômades, ao realizarem ocupações de terra urbana ou ao serem beneficiados com unidades habitacionais, imprimem um significado ao bem adquirido que transcende a ideia de direito à moradia. Nesse sentido, os nômades urbanos desejam consumir o bem não somente para fins de habitação, mas também como um bem de mercado, que pode ser vendido, obtendo-se lucro com a negociação. Desse modo, reivindicam não somente o direito à moradia, mas, também, direito à propriedade do bem.

Ao longo desse trabalho, tentei mostrar que a visão de mundo dos nômades urbanos - no que diz respeito à legalidade ou ilegalidade de uma ação de ocupação ou remoção e à regularidade ou irregularidade do modo como os mesmos habitam na cidade - recebe influência de múltiplas fontes, propiciando a formação de códigos e significados extremamente heterogêneos. Nesse sentido, nas suas variadas apropriações sobre as normas que regem a questão fundiária urbana, os nômades recebem influência de fontes diversas, tais como: Igreja; instituições ligadas a movimentos sociais em prol do direito à moradia; associações de bairros e favelas; lideranças comunitárias; advogados, vereadores, deputados, líderes de ocupação, dentre outras. Essa multiplicidade cultural que encontrei em minha pesquisa, típica das sociedades complexas, me levou a concluir que há muito mais heterogeneidade e diversidade do que encontros de blocos monolíticos na forma como os nômades urbanos e a rede de agentes que se formam em torno das suas ações concebem as normas jurídicas emanadas do Estado. 
Nesse sentido, a ideia de moradia legítima também pode variar entre os próprios moradores da favela, conjunto habitacional ou assentamento irregular. Se para o Estado todos esses habitantes são considerados invasores e ocupantes irregulares, para os moradores locais existem critérios variados de diferenciação, no que diz respeito, por exemplo, ao lugar onde suas casas se situam na favela, à qualidade de construção das mesmas, à profissão exercida pelos moradores, dentre outros. No caso da Favela da Maravilha, alguns moradores, residentes em casas maiores e mais bem acabadas, não se consideram habitantes da favela e resistiram muito à remoção. Nesse sentido, é importante enfatizar o aspecto político do desvio, de acordo com Becker:

A questão de qual é o objetivo ou meta (função) de um grupo $\mathrm{e}$, consequentemente, de que coisas vão ajudar ou atrapalhar a realização desse objetivo - é muitas vezes política. Facções de grupos descordam e manobram para ter sua própria definição da função do grupo aceita. A função do grupo ou organização, portanto, é decidida em conflito político, não dada na natureza da organização. Se isso for verdade, é igualmente verdadeiro que as questões de quais regras devem ser impostas, que comportamentos vistos como desviantes e que pessoas rotuladas como outsiders devem também ser encarados como políticas. A concepção funcional do desvio, ao ignorar o aspecto político do fenômeno, limita nossa compreensão. (2008, p. 20, grifo meu)

Assim, o desvio não é algo que está exatamente na natureza ou essência da ação em si, é uma disputa política que será, geralmente, vencida por aqueles que estão no topo da hierarquia de um sistema. Sabe-se que as regras sociais são criações de grupos específicos e que as sociedades complexas são dotadas de uma multiplicidade de códigos socioculturais que variam de acordo com categorias de classe social, étnicas, etárias, ocupacionais, culturais. Os diversos agentes envolvidos no processo de disputa pela terra urbana não precisam partilhar as mesmas regras e, geralmente, não o fazem, gerando conflitos. Nesse sentido questiona Becker: "quem, de fato, obriga outros a aceitar suas regras e quais são as causas de seu sucesso? Esta é, claro, uma questão de poder político e econômico". (2008, p. 29)

Mas, essa batalha, muitas vezes, pode não ter resultados eficazes, isso ocorre quando a pessoa julgada como desviante não aceita as regras que lhes são impostas nem os juízes que tentam frustradamente aplicá-las. Nesse caso os “outsiders”, a partir da visão da pessoa que é rotulada como desviante, podem ser aqueles que fazem as regras de cuja violação ela foi considerada culpada. O desviante, nesse caso, cria seus próprios 
conceitos de conduta legítima, estabelece outros códigos e elege novos juízes ou interpreta as normas de direito positivo a seu favor, confrontando-as com a interpretação dos poderes estabelecidos. Nesse sentido, o caso da Dona Íris, moradora da Praia das Goiabeiras, em sua trajetória de luta e resistência contra a remoção, quando ela diz que comprou sua casa do Governo do Estado na década de 1980 e passou 25 anos pagando. A moradora nega a condição de invasora, de ocupante ilegal, imposta pelo Estado, uma vez que seu conjunto habitacional foi construído em terreno de marinha, área pertencente à União. Ela afirma que invasor é o Estado do Ceará que foi quem construiu o conjunto e vendeu as casas para a população. Afirmando a sua condição de proprietária do terreno, a moradora se nega a ser removida. Mas, diz que se não tiver como impedir a ação de remoção, vai lutar pelo direito a uma indenização justa, que contemple o valor do imóvel e não somente da benfeitoria construída no mesmo. Ao contrário da maioria dos seus vizinhos, a moradora afirma que não está brigando com o Estado, mas: lutando pelos seus direitos!

A questão central do outsider é que as regras e os desvios são produtos de uma ação coletiva e, além disso, não são universalmente aceitas, ao contrário, são objeto de conflito e discordância na permanente negociação da realidade, que faz parte do processo político da sociedade. Segundo Becker:

[...] grupos sociais criam desvio ao fazer as regras cuja infração constitui desvio, e ao aplicar essas regras a pessoas particulares e rotulá-las como outsiders. Desse ponto de vista, o desvio não é uma qualidade do ato que a pessoa comete, mas uma consequência da aplicação por outros de regras e sanções a um "infrator". O desviante é alguém a quem esse rótulo foi aplicado com sucesso; o comportamento desviante é aquele que as pessoas rotulam como tal. (2008, p. 22, grifo meu)

Com isso, percebe-se que o desvio não é uma qualidade simples, que pode estar presente em algumas condutas e ausentes em outras. É antes de tudo um processo político que envolve reações de outras pessoas ao comportamento. Um mesmo comportamento poder receber o rótulo de desviante em uma situação e em outra não; pode ser uma infração às regras quando cometido por uma pessoa, mas quando realizado por outra não; algumas regras são descumpridas com impunidade, outras não. Desse modo, se um dado ato é desviante ou não, depende em parte da natureza do ato (ou seja, se o mesmo violou ou não uma regra) e em parte de como as pessoas reagem a esse ato. Em suma, o desvio não é uma qualidade inerente ao comportamento em si, 
mas a interação entre a pessoa que comete um ato e aquelas que reagem a ele. $\mathrm{O}$ desvio é produto de uma ação coletiva. No caso das ocupações ocorridas na Praia do Futuro, em um dos terrenos ocupados, os nômades construíram um barraco, no qual uma jovem grávida ficou residindo sozinha durante os dias de tentativa da ocupação. A proprietária desse terreno chegou ao local e tentou negociar com a ocupante, pedindo que ela saísse. Em troca, a proprietária ofereceu à gestante, todo o seu pré-natal, um salário mínimo e uma cesta básica. A ocupante aceitou a proposta e desocupou o local. Em seguida, os seguranças particulares da proprietária demoliram o barraco. A gestante desapareceu, pois foi ameaçada de linchamento pela população que estava participando da ocupação.

Desse modo, para a proprietária os nômades urbanos estavam praticando um ato desviante, ilegal, pois invadiram o seu terreno, ferindo o seu direito de propriedade. Para os nômades o ato era legítimo, pois estavam exercendo o seu direito à moradia. A moça gestante havia aderido à ação coletiva de ocupação do terreno e aceitou ficar habitando no barraco, até que a ocupação fosse totalmente efetivada, momento em que ficaria decidido qual seria, realmente, o seu lote de terra. No entanto, a moça grávida resolveu desobedecer às regras estabelecidas pelo grupo, desfazendo o pacto que havia feito com os mesmos. Nesse momento, a gestante praticou um ato desviante de acordo com os códigos de conduta estabelecidos pelos nômades.

É interessante com ideia de desvio é empregada de maneira mais rígida à segunda categoria de nômade (nômades negociantes), ou seja, daqueles que ocupam terrenos para comercializar. Essa ação é reprovada pela maioria dos agentes, inclusive pelas associações ligadas aos movimentos sociais de luta por moradia e não encontra proteção em nenhuma regra jurídica de direito social. Essa ação, conforme já analisado, é altamente recriminada, constituindo, ainda, uma forma de deslegitimar a luta dos movimentos sociais. Mas, para os nômades envolvidos nessas ocupações de comercio de lotes, a ação é uma espécie de profissão, um meio de vida. Gostaria de chamar atenção para essa segunda espécie de nômades que faz das ocupações urbanas uma forma de ganhar dinheiro. A partir dos dados colhidos em campo, percebi que realmente existia um aspecto de caráter vocacional envolvido no movimento desse segundo tipo de nômades.

De acordo com Simmel (2005), a vida nas metrópoles é pautada pelos inevitáveis processos de objetivação das relações sociais. As sociedades vivem das 
diferenças, são as diferenças que permitem a vida social e as metrópoles são, por excelência, o local onde estas diferenças melhor se apresentam. É a parir dessa realidade que se dá a interação social. Os indivíduos interagem porque são diferentes. E a tarefa do antropólogo é se perguntar até que ponto as diferenças que aparecem na metrópole podem ser negociadas? Até que ponto as pessoas que fazem parte de um mesmo drama social podem participar de diálogos?

Nesse sentido, aceitar o ato de ocupar terrenos com o objetivo de vender os lotes para outras pessoas que não podem adquirir uma moradia dentro de um mercado formal é, a partir do julgamento dos códigos morais e das normas jurídicas predominantes em nossa sociedade, um ato desviante, reprovável. Por outro lado, percebi, na minha pesquisa de campo, que essa prática é frequente em Fortaleza. Nem sempre a população desprovida de moradia se organiza para ocupar um terreno. Em muitos casos, são segmentos que fazem esse trabalho difícil, conflituoso e, muitas vezes, violentos de conseguir efetivar uma ocupação.

A população de classe média e alta, quando vai adquirir uma casa própria, procura, no mercado imobiliário, empresas e corretores que fazem a mediação entre o interesse do cliente e as ofertas do mercado, mostrando imóveis que sejam adequados às suas possibilidades e necessidades. Quando o cliente escolhe o imóvel a ser comprado, a imobiliária ou o corretor autônomo recebe uma comissão pela venda. Todos esses tramites são controlados e regulamentados por órgãos da categoria profissional de corretores, como o Conselho Regional de Corretores de Imóveis do Ceará.

Mas, as pessoas que não têm renda suficiente para adquirir uma moradia dentro dos moldes da legalidade, procuram esses grupos clandestinos, geralmente chefiados por líderes comunitários, aceitando o preço cobrado por eles. Esses intermediários entre os interesses da população carente de moradia e a realização das ocupações são considerados "aproveitadores", são outsiders no exercício de sua função. Conforme já ressaltado, a ação de ocupar um terreno é perigosa e violenta, na maioria das vezes, e nem todos estão dispostos a participar do evento. Preferem, assim, pagar o preço do risco a um líder comunitário que forma um grupo para executar a ocupação. Os códigos, regras e pactos que vigoram nesse evento são criados e aceitos pela própria população nômade que também recebem apoio de políticos, advogados e associações ligadas aos direitos humanos, principalmente quando a tentativa de ocupação ocorre próxima ao período eleitoral. 
Assim, o processo de ocupação de um terreno é composto de duas etapas básicas. A primeira consiste na própria ação de "invadir", "ocupar" o terreno. Nem todas as pessoas que participam dessa ação têm interesse em adquirir uma moradia. Muitas se envolvem no evento com o objetivo de adquirir lotes de terra para comercializar. Desse modo, os nômades negociantes fazem do processo de ocupação uma profissão, um meio de ganhar a vida. Estes grupos, então, são responsáveis por efetivar a ocupação, participando de todos os conflitos inerentes a esse evento, que pode, muitas vezes, se assemelhar a uma verdadeira guerra, conforme os exemplos já citados das minhas experiências empíricas com a ocupação de terrenos na Praia do Futuro. Se o terreno for ocupado com sucesso, ocorre a segunda etapa, na qual o grupo que liderou vai vender os terrenos loteados para quem deseja comprar. Os preços dos lotes variam, conforme a benfeitoria que for feita no terreno. Se o lote está apenas demarcado, se já se construiu uma casa no mesmo, se a casa está acabada por dentro e com pintura. Todos esses fatores influenciam no preço da venda do imóvel e no quanto o líder ou líderes da ocupação vão lucrar com os mesmos. É muito comum também, pessoas comprarem lotes para construir casas e quartos para alugar e viverem da renda dos aluguéis, como é o caso da Jeane, moradora da Maravilha. Outros compram casas para trazer parentes e amigos do interior.

Segundo Simmel: "As grandes cidades sempre foram o lugar da economia monetária, porque a multiplicidade e concentração da troca econômica dão ao meio de troca uma importância que não existiria na escassez da troca do campo.” (2005, p. 578) Nesse sentido, o solo, na cidade grande, é uma mercadoria que se troca como qualquer outra. Esse mercado de troca é envolvido pela luta que se tece em torno do espaço urbano. Nessa disputa, criam-se novas profissões que tem por objetivos apropriar-se do solo urbano e vendê-lo de modo cada vez mais lucrativo. Então, aparecem empresas e profissionais cada vez mais especializadas na comercialização de imóveis: construtoras, incorporadoras, empresas imobiliárias, corretores, engenheiros, arquitetos, dentre outros. Nesse sentido, explica Simmel que:

As cidades são, em primeiro lugar, a sede da mais alta divisão econômica do trabalho. Produzem, portanto, fenômenos tão extremos quanto, em Paris, a ocupação remunerada do quatorziéme. São pessoas que se identificam por meio de avisos em suas residências e que estão prontas, à hora do jantar, corretamente trajadas, de modo que possam ser rapidamente convocadas, caso um jantar consista em treze pessoas. $\mathrm{Na}$ 
medida de sua expansão, a cidade oferece mais e mais as condições decisivas da divisão de trabalho. (1979, p. 21)

Simmel escreveu esse texto no começo do século passado, revelando a realidade das grandes cidades de mais de cem anos atrás. No entanto, o fenômeno da grandeza funcional das cidades e, consequente, divisão econômica do trabalho continuam extremamente atuais, em proporções cada vez maiores e mais sofisticadas. Isso acontece em todas as classes sociais, principalmente em um País como o Brasil, onde grade parte da população vive de uma economia informal. É natural, assim, que se desenvolvam profissões informais, clandestinas, consideradas desviantes, no sentido já mencionado da teoria de Becker.

Assim, a partir da realidade que encontrei em campo e da teoria apresentada nesta pesquisa, concebo a ação dos nômades negociantes, através do desenvolvimento de um caráter vocacional, ou seja, de grupos de fazem das ocupações um meio de vida.

As ocupações urbanas, no entanto, são dotadas de um caráter extremamente heterogêneo. Desse modo, não é fácil distinguir quando uma ocupação é realizada como trabalho e quando uma ocupação é realizada como o intuito de obter moradias. Num mesmo evento de ocupação essas categorias se misturam como podem, também, predominar uma sobre a outra, dependendo do caso.

Segundo Park (1967), toda situação que proporciona o desenvolvimento do comércio e da indústria abre espaço para uma nova divisão do trabalho, especializando as tarefas nas quais o homem encontra suas vocações. A consequência desse acontecimento é o rompimento ou transformação da organização social e econômica anterior, baseada em relações familiares, associações locais, na tradição, castas e status, e sua substituição por uma organização baseada em interesses ocupacionais e vocacionais, pois a cidade oferece um mercado para os talentos e as condições específicas de desenvolvimento dos indivíduos. Assim, como as relações nas cidades são baseadas no poder de troca que dá lugar à divisão do trabalho, quanto maior o mercado, maior as especificidades de funções desenvolvidas pelos indivíduos. Há determinadas atividades, portanto, que não poderiam ser desenvolvidas se não em grandes cidades. Nas palavras de Park: 
$\mathrm{Na}$ cidade, qualquer vocação, mesmo a de mendigo, tende a assumir o caráter de profissão, e a disciplina que em qualquer vocação o sucesso impõe, junto com as associações a que dá força, acentua essa tendência - a tendência, explicitamente, não apenas de especializar, mas de racionalizar a ocupação de alguém e de desenvolver uma técnica consciente e específica de levá-la a termo. (1967, p. 41, grifo meu)

Conforme o pensamento do autor nas cidades existem várias ocupações que, apesar de serem estigmatizadas e vistas como desviantes, tem caráter de trabalho e profissão. Becker (1977), ao estudar os tipos de comportamento desviantes, também utiliza a concepção de carreira, analisando o desvio como produto de um processo da ação coletiva. $\mathrm{O}$ autor focaliza o seu estudo em pessoas que fazem do desvio uma maneira de viver, organizando sua identidade em torno de um padrão de comportamento desviante. Muitos dos tipos de atividades desviantes provêm de motivos socialmente aprendidos. Geralmente, antes de se envolver na atividade em bases mais ou menos regulares, a pessoa não tem noção dos benefícios que dela podem ser obtidos, tomando conhecimento deles no curso da interação com desviantes mais experientes. Um ato desviante poder iniciar-se através de um impulso aleatório de experimentar algo novo, tornando-se, posteriormente, um gosto estabelecido por algo já conhecido e experimentado.

Na experiência empírica que tive nas ocupações da Praia do Futuro, pude constatar essa realidade. O líder da ocupação aparentava ser um homem de mais de quarenta anos. Segundo informações que obtive através de moradores da barra do Rio Cocó, ele não era morador antigo da "comunidade". Veio de Pernambuco e havia chegado a Fortaleza há alguns meses. Alugou um quarto, próximo aos terrenos que seriam alvo da tentativa de ocupação, passou dois meses estudando o local, fazendo contato com políticos e advogados e convencendo a população a se envolver no evento, prometendo lotes, caso a tentativa tivesse sucesso. Ele ganharia uma porcentagem em cima de cada lote ocupado. No início, poucas pessoas aderiram ao evento, cerca de dez homens. Mas, depois de quatro dias que a ocupação havia começado, chegaram mulheres e crianças. As crianças receberam cinco reais do líder da ocupação para ajudar a derrubar os murros. As mulheres seriam beneficiadas com lotes maiores, que depois venderiam para familiares vindos do interior ou terceiros interessados. Depois, de três dias do início da ocupação, duas mulheres passaram, também, a liderar o evento. Uma tinha vinte poucos anos e se responsabilizava em ligar para os advogados, sempre que 
houvesse alguma ameaça por parte dos proprietários do terreno, ela passava grande parte do tempo falando ao celular. A outra aparentava ter uns quarenta anos e se responsabilizava, com a ajuda de outras pessoas, pela demarcação e divisão dos lotes com fios de náilon e estacas. Ambas, também ganhariam uma porcentagem nas vendas dos lotes. E, assim, o grupo foi crescendo, ao ponto de, no dia da desocupação, quando o oficial de justiça chegou com uma ordem judicial oriunda de uma decisão liminar em favor do proprietário, haver muitas pessoas dentro do terreno. Nesse sentido, quero mostrar, de acordo com o pensamento de Becker, como o desvio é fruto de uma ação coletiva.

Ao apontar para essa realidade, a presente pesquisa não tem o objetivo deslegitimar as ações dos movimentos sócias que exercem um importante papel no processo histórico de luta por moradia urbana e que têm sido responsáveis pelo reconhecimento e afirmação do direito à uma cidade mais justa e igualitária, conforme já explicitado na introdução deste trabalho. Quero, no entanto, chamar a atenção para o fato de que o movimento de disputa pela terra urbana é extremamente heterogêneo e hierarquizado, pois ao mesmo tempo em que expressa os valores de igualdade $\mathrm{e}$ colabora para a efetivação de direitos sociais, é trançado por um emaranhado de linhas que compõe redes de interesses diversas e expressam valores próprios aos diferentes grupos e poderes envolvidos, transcendendo as normas escritas do direito estatal e compondo um permanente jogo de negociação da realidade social.

Desse modo, um processo de ocupação urbana pode iniciar-se a partir da ação coletiva de pessoas que se unem para conseguir um lote de terra para morar, predominado, nesse caso, o primeiro tipo de nômade (nômades moradores). Mas, depois de efetivada a ocupação, as pessoas que participaram do evento, pelos mais diversos motivos, podem construir suas casas e logo depois, vender, como podem, também, permanecer mais tempo no local e, após alguns anos, se desfazer do imóvel. Podem, ainda, tornarem-se sedentárias e nunca se desfazer do terreno ocupado, chegando a transmiti-los para seus herdeiros, até o dia em que o local possa sofrer uma ação de intervenção urbana, como remoção de favela, por exemplo. No entanto, o que há de permanente nas ocupações urbanas é o significado jurídico que os nômades imprimem às mesmas, ou seja, ao se apossarem de um imóvel, os ocupantes querem utilizar o bem não somente para fins de moradia, mas também como um bem de mercado, que pode ser negociado e vendido. Com isso, quero reforçar a ideia de que os 
nômades, nos seus movimentos de ocupações urbanas, desejam ter garantido não somente o direito à moradia, mas, também, à propriedade privada.

Desse modo, esta pesquisa procurou compreender como as ações de disputa pela terra urbana se dão do ponto de vista dos nômades, preocupando-se com as formas e usos que essa população faz das ocupações.

Como todo grupo profissional, as pessoas envolvidas na organização do espaço urbano (Poder Público, empresas imobiliárias, engenheiros, arquitetos, legisladores, organizações não governamentais, assistentes sociais, dentre outros) têm seus próprios interesses e perspectivas a proteger. Nesse sentido, percebi que é muito óbvio colocar a responsabilidade pela não fixação de pessoas em moradias regulares ou pela prática do comércio clandestino de lotes e unidades habitacionais nos nômades urbanos. Já foi dito que essas pessoas não agem sozinhas, existe toda uma rede de poderes e interesses que se forma em torno da disputa dos nômades pela terra urbana, seja para morar, seja para lucrar com a comercialização do solo. Assim, todos os agentes envolvidos nesse drama social contribuem para o que nela acontece. É por isso que insisto na importância do estudo dessas redes de poder e no jogo de interesses e produção de significados que nela se tecem.

Neste trabalho, procurei explorar a própria visão de mundo dos nômades urbanos, de como eles classificam o modo de morar na cidade, o que é uma moradia legal, o que legitima o direito à negociação de imóveis em função da sua relação com o espaço. Preocupei-me, portanto, com as representações dessa população, como se situam no mundo, como organizam e classificam a sociedade. É importante ressaltar, no entanto, a sua não-autonomia como segmentos, pois os nômades urbanos não são os únicos produtores dos símbolos e aspirações que circundam suas estratégias de vida e decisões existenciais.

A dos nômades urbanos foi um ponto de partida para tentar fazer uma análise sistemática do estilo de habitar na cidade e da visão de mundo desses moradores de áreas segregadas. Percebe-se, assim, que existe uma questão política fundamental envolvida nessa problemática, qual seja, o fato de que os nômades estão sujeitos, no seu dia-a-dia, a uma série de ameaças e inseguranças, vivem clandestinamente, sempre com medo de serem descoberto, expulsos ou removidos de suas moradias por estarem na condição de habitantes "informais" e "ilegais", sendo constantemente acusados e 
estigmatizados. Desse modo, em uma sociedade disciplinar (FOUCAULT, 2008) existem organismos sociais de controle, normas jurídicas, projetos de intervenção urbana, autoridades ou cidadãos comuns que interferem constantemente no seu modo de vida, impondo padrões de conduta e de moradia, utilizando a coerção para impedi-los de fazer coisas que julgam corretas ou desejáveis.

Com níveis diferentes de intensidade, os nômades são instigados a desenvolver estratégias sofisticadas para poderem exercer o direito à moradia, ao trabalho, ao lazer, etc. Segundo Simmel (2005), as grandes cidades sempre foram o lugar da economia monetária que é responsável por uma intensa objetivação das relações humanas. Independentemente disso, o autor chama a atenção para a resistência do sujeito a ser nivelado e consumido em um mecanismo técnico-social e é isso que podemos perceber no movimento de nomadismo das populações dentro do espaço urbano que estão sempre desenvolvendo novas estratégias de sobrevivência, na criação de novas formas de existência e de divisão do trabalho, de novas profissões, vocações e locais de moradia. Essa cultura objetiva e racional da cidade grande, ao mesmo tempo em que esmaga e oprime essas populações, também oferece uma multiplicidade de possibilidades na reinvenção da vida social. Simmel, fala, que "o fundamento psicológico sobre o qual se eleva o tipo das individualidades da cidade grande é a intensificação da vida nervosa, que resulta da mudança rápida e ininterrupta de impressões interiores e exteriores" (2005, p. 578, grifo do autor)

As ações dos nômades urbanos constituem, assim, uma linha de fuga na tentativa de não se deixar subsumir aos mecanismos de controle do poder que procuram disciplinar os corpos e "higienizar" os espaços da cidade. Conforme Simmel, "o habitante da cidade grande, que é naturalmente envolto em milhares de modificações individuais, cria um órgão protetor contra o desenraizamento com o qual as correntes e discrepâncias de seu meio exterior o ameaçam" (2005, p. 578, grifo meu). Assim, segundo Simmel, o habitante da cidade grande desenvolve mecanismos protetores contra $\mathrm{o}$ desenraizamento, contra a diversidade e heterogeneidade de estímulos que são típicos do meio ambiente urbano.

Entendo desse modo, que o constante processo de territorialização e desterritorialização dos nômades urbanos constitui um alto grau de desenvolvimento de preservativo da vida subjetiva frente à coação da grande cidade. É uma espécie de 
imunidade criada por essa população em face da racionalidade e objetividade da vida nas metrópoles contemporâneas.

É importante ressaltar aqui a ideia de Ecologia Humana desenvolvida por Robert Park (1967), no sentido de que a cidade é muito mais do que um mecanismo físico e do que uma construção artificial, ela está envolvida nos processos vitais das pessoas que a compõem, é um produto da natureza humana, participando assim no processo de formação da visão do mundo de seus habitantes.

No estudo das travessias dos nômades urbanos na cidade de Fortaleza, tentei mostrar como são traçados mapas simbólicos e de prestígio que se sobrepõem aos mapas oficiais do Estado sobre a cidade. Procurei entender como a ação dos nômades urbanos pode constituir um campo possível de renovação da vida, na tentativa de reinventar novos critérios de produção social da existência.

\section{5 - Bibliografia}

BARTH, Fredrik. Tradução John Cunha Comerford. $O$ guru, o iniciador e outras variações antropológicas. Rio de Janeiro: Contra Capa, 2000.

BECKER, Howord S. Tradução de Maria Luiza X. de A. Borges. Outsiders: estudos de sociologia do desvio. Rio de Janeiro: Jorge Zahar Ed., 2008.

. Tradução de Márcia Bandeira de Mello L. Nunes. Uma Teoria da Ação Coletiva. Rio de Janeiro: Zahar, 1977.

. Tradução de Maria Luiza X. de A. Borges. Segredos e truques da pesquisa. Rio de Janeiro: Jorge Zahar, 2007.

BRASIL, Constituição Federal 1988.

DELEUZE, Gilles, GUATTARI, Félix. Tradução. Peter Pál Pelbart e Janice Caiafa. Mil platôs: capitalismo e esquizofrenia, vol. 5. São Paulo: Editora 34, 1997.

, PARNET, Claire. Tradução de Eloisa Araújo Ribeiro. Diálogos.

São Paulo: Editora Escuta, 1998.

, Tradução Luiz Orlandi e Roberto Machado. Diferença e Repetição.

$2^{\text {a }}$ Ed. São Paulo: Graal, 2006.

DURKHEIM, Emile, e MAUSS, Marcel, De quelquers formes primitives de classification, in Mauss, Marcel, Essais de Sociologie, Editions de Minuit, Paris, 1966 e 1969.

FOUCAULT, Michel. Tradução Roberto Machado. Microfísica do poder. 25 a edição. Rio de Janeiro: Editora Graal, 2008.

XIV, 1995.

.Discipline and punish: the birth of the prison. New York: XI- 
GEERTZ, Clifford. A Interpretação das Culturas. Rio de Janeiro: LTC, 2008.

. O Saber Local: novos ensaios em antropologia interpretativa. $2^{\text {a }}$ edição. Tradução de Vera Mello Joscelyne. Petrópolis: Editora Vozes, 1999.

GOLDMAN, Marcio. Antropologia Contemporânea, Sociedades Complexas e Outras Questões. Anuário Antropológico/93. Rio de Janeiro: Tempo Brasileiro, 1995.

GUATTARI, Félix e ROLNIK, Suely. Micropolítica: cartografias do desejo. Rio de Janeiro: Vezes, 1986.

. Caosmose: um novo paradigma estético. Tradução de Ana Lúcia de Oliveira e Lúcia Cláudia Leão. São Paulo: Ed. 34, 1992.

. As três ecologias. 16 ${ }^{\mathrm{a}}$ ed. Tradução Maria Cristina F. Bittencourt. São Paulo: Papirus Editora, 2005.

PARK, Robert E. Tradução Sérgio Magalhães Santerio. A Cidade: sugestões para a investigação do comportamento humano no meio urbano. In: VELHO, O. (Org.) $O$ fenômeno urbano. Rio de Janeio: Zahar, 1967.

REALE, Miguel. Lições Preliminares de Direito. 27ª Ed. São Paulo: Saraiva, 2004.

ROCHA, Ana Luiza Carvalho da, ECKERT, Cornelia. O tempo e a cidade. Porto alegre: editora da UFRGS, 2005.

ROLNIK, Raquel e SAULE JÚNIOR, Nelson coordenadores. Estatuto da Cidade: guia para implementação pelos municípios e cidadãos. Brasília: Câmara dos Deputados, 2001.

.O que é cidade. 3 ed. São Paulo: Brasiliense, 1995.

SIMMEL, Georg. Tradução David Rodgers e Michele Markowitz. As Grandes Cidades e a Vida do Espírito (1903) in: Mana: Estudos de Antropologia Social, volume 11, número 2. Museu Nacional, Departamento de Antropologia, Programa de Pós- Graduação em Antropologia Social. Rio de Janeiro: 2005.

. Tradução Sérgio Marques dos Reis. A Metrópole e a Vida Mental. in: O Fenômeno Urbano. Organização de Otávio Guilherme Velho. $4^{a}$ edição. Rio de Janeiro: Zahar, 1979.

SOUZA, Maria Ângela de Almeida. Habitação: Bem ou Direito? O Dilema da Promoção Pública da Habitação Popular. In: NASCIMENTO, E. P.; BARREIRA, I. L. F. (Org). Brasil Urbano: Cenários da Ordem e da Desordem. Rio de Janeiro: Editora Notrya, 1993.

VELHO, Gilberto. Projeto e Metamorfose: antropologia das sociedades complexas. $3^{\text {a }}$ edição. Rio de Janeiro: Zahar, 2003 a.

. Nobres \& Anjos: um estudo de tóxicos e hierarquia. $2{ }^{\text {a }}$ edição. Rio de Janeiro: Zahar, 2008a.

. Individualismo e Cultura: notas para uma antropologia da sociedade contemporânea. $8^{\mathrm{a}}$ edição. Rio de Janeiro:Zahar, 2008b. 
. Metrópole, cultura e conflito. VELHO, G. (Org.), in Rio de Janeiro: cultura, política e conflito. Rio de Janeio: Zahar, 2007.

de Janeiro: Zahar, 1989.

. A Utopia Urbana: um estudo de antropologia social. $5^{\text {a }}$ edição. Rio

O Estudo do Comportamento Desviante: A Contribuição da Antropologia Social. In: Desvio e Divergência: uma crítica da patologia social. VELHO, G. (Org.). 6ª edição. Rio de Janeiro: Zahar, 1985.

e KUSCHNIR, K. (org.) Pesquisas urbanas: desafios do trabalho antropológico. Rio de Janeiro: Jorge Zahar, $2003 \mathrm{~b}$.

Os Mundos de Copacabana. In: Antropologia Urbana: cultura e sociedade no Brasil e em Portugal. VELHO, G. (org.). Rio de Janeiro: Jorge Zahar, 2006.

WEBER, Max. Tradução Regis Barbosa e Karen Elsabe Barbosa. Economia e Sociedade. $3^{\text {a }}$ edição, vol. 1 e 2. São Paulo: Editora UnB: 1994.

ZALUAR, Alba. Crime, Medo e Política, in: Um Século de Favela. Organização Alba Zaluar e Marcos Alvito. $5^{\text {a }}$ ed. Rio de Janeiro: Editora FGV, 2006.

, ALVITO, Marcos. Introdução, in: Um século de favela. Organização Alba Zaluar e Marcos Alvito. $5^{\text {a }}$. ed. Rio de Janeiro: Fundação Getulio Vargas, 2006. 